\title{
Nasal cancer in England and Wales: an occupational survey
}

\author{
E D ACHESON, ${ }^{1}$ R H COWDELL, ${ }^{2}$ AND E H RANG ${ }^{3}$ \\ From the MRC Environmental Epidemiology Unit, Southampton General Hospital, ${ }^{1}$ Department of \\ Pathology, Radcliffe Infirmary, Oxford, ${ }^{2}$ and Department of Surgery, St George's Hospital, London, ${ }^{3}$ UK
}

ABSTRACT A national survey of the incidence of nasal cancer in England and Wales during the period 1963-7 with special reference to occupation confirmed the well-known increases in incidence of nasal cancer in cabinet makers and wood machinists, together with the absence of any significant increase in carpenters and joiners, and the increases in boot and shoe operatives and repairers, and in nickel smelters in South Wales. The significant excesses of cases found among coalminers, furnacemen in the gas, coke, and chemical industry, and furnacemen and labourers in foundries may be associated with exposure to coal and coke dust or may be spurious. No excess of nasal cancer was found among male textile workers. Excesses of uncertain significance were found among tailors and dressmakers, bakers and pastry cooks, and printers. Apart from the well-known relationships between adenocarcinoma and work in the furniture and footwear industries there is no definite indication in this survey of any association between a particular histological type of nasal tumour and occupation in England and Wales.

In 1965 Hadfield and Macbeth ${ }^{1}$ noted an association between adenocarcinoma of the nasal cavity and work in the furniture industry in Buckinghamshire. Subsequent epidemiological surveys have shown that the development of these tumours is a risk associated with the inhalation of wood dust by workers in the furniture industry throughout England and Wales and many other countries but not among carpenters. ${ }^{2} 3$

Nasal carcinomas of various histological types and especially adenocarcinoma are also prevalent among those operatives in Britain (chiefly men) who carry out dusty work in the manufacture and repair of boots and shoes. ${ }^{4}$ Recently, shoemakers and shoe repairers in the province of Florence have also been found to be at risk in respect of adenocarcinoma. ${ }^{5}$

\section{Methods}

The Office of Population Censuses and Surveys provided copies of the cancer registration forms for

Requests for reprints to: Professor E D Acheson, MRC Environmental Epidemiology Unit, South Academic Block, Southampton General Hospital, Southampton SO9 4XY.

Received 7 August 1980

Accepted 10 September 1980 all cases of malignant neoplasm of the nose, nasal cavities, middle ear, and accessory sinuses (ICD code 160) ${ }^{6}$ registered in England and Wales during the five-year period 1963-7. These forms include details of the hospital in which the patient was treated. The hospitals were contacted and invited to notify for each patient the name and address of the general practitioner and any occupational data that had been recorded in the notes. The consultant pathologists at the hospital were asked to send histological material to one of us (RHC) wherever possible so that the classification of the tumours could be standardised.

A letter to the general practitioner of each patient asked for permission to approach the patient, or if he had died a close relative, for information about the occupational history and smoking and snuffing habits. Where permission was granted a letter was sent explaining the purpose of the study and inviting the patient or relative to help us by giving full details of all occupations held from time of leaving school to the time of diagnosis of the tumour. The informants were also asked to complete a simple questionnaire on smoking and snuffing habits. Full identification details and the occupational, histological, and smoking and snuffing information obtained from the various postal inquiries were 
Table 1 Observed and expected numbers of cases of nasal cancer (men) distributed by occupational order with standard incidence ratios

\begin{tabular}{|c|c|c|c|c|c|}
\hline \multicolumn{2}{|c|}{ Occupational order } & \multirow{2}{*}{$\begin{array}{l}\begin{array}{l}\text { Observed } \\
\text { cases }\end{array} \\
55\end{array}$} & \multirow{2}{*}{$\begin{array}{l}\begin{array}{l}\text { Expected } \\
\text { cases }\end{array} \\
58 \cdot 0\end{array}$} & \multirow{2}{*}{$\begin{array}{l}\begin{array}{l}\text { Standardised } \\
\text { incidence ratio }\end{array} \\
95\end{array}$} & \multirow[t]{2}{*}{ p-value $†$} \\
\hline I & Farmers, foresters, fishermen & & & & \\
\hline II & Miners and quarrymen & 52 & $31 \cdot 4$ & 165 & $* *$ \\
\hline III & Gas, coke, and chemical workers & 12 & $6 \cdot 5$ & 185 & \\
\hline IV & Glass and ceramics makers & 5 & $3 \cdot 3$ & 153 & \\
\hline V & Furnace, forge, foundry, rolling mill workers & 29 & $11 \cdot 6$ & 250 & ** \\
\hline VI & Electrical and electronic workers & 11 & $16 \cdot 3$ & 68 & \\
\hline VII & Engineering and allied trade workers & 85 & $101 \cdot 3$ & 84 & \\
\hline VIII & Woodworkers & 59 & $20 \cdot 8$ & 284 & ** \\
\hline IX & Leather workers & 26 & $6 \cdot 0$ & 436 & ** \\
\hline $\mathbf{X}$ & Textile workers & 10 & $10 \cdot 5$ & 95 & \\
\hline XI & Clothing workers & 12 & $5 \cdot 7$ & 209 & $*$ \\
\hline $\mathbf{X I I}$ & Food, drink, and tobacco workers & 22 & $14 \cdot 9$ & 148 & \\
\hline XIII & Paper and printing workers & 15 & $10 \cdot 1$ & 148 & \\
\hline XIV & Makers of other products & 5 & $8 \cdot 0$ & 62 & \\
\hline XV & Construction workers & 17 & $31 \cdot 4$ & 54 & $* *$ \\
\hline XVI & Painters and decorators & 23 & $16 \cdot 5$ & 139 & \\
\hline XVII & Drivers of stationary engines & 18 & $18 \cdot 7$ & 96 & \\
\hline XVIII & Labourers (not elswhere classified) & 67 & $81 \cdot 6$ & 82 & \\
\hline XIX & Transport and communication workers & 86 & $69 \cdot 9$ & 123 & \\
\hline $\mathbf{X X}$ & Warehousemen, storekeepers, etc & 28 & $36 \cdot 5$ & 77 & \\
\hline $\mathbf{X X I}$ & Clerical workers & 55 & $69 \cdot 8$ & 79 & \\
\hline XXII & Sales workers & 54 & $72 \cdot 5$ & 74 & $*$ \\
\hline XXIII & Service, sport, and recreation workers & 54 & $63 \cdot 9$ & 85 & \\
\hline XXIV & Administrators and managers & 23 & $44 \cdot 1$ & 52 & $* *$ \\
\hline XXV & Professional, technical workers, artists & 45 & $60 \cdot 6$ & 74 & $*$ \\
\hline XXVI & Armed Forces & 7 & $4 \cdot 8$ & 146 & \\
\hline XXVII & Inadequately described or no known occupation & 50 & $50 \cdot 3$ & 99 & \\
\hline All & & 925 & 925 & 100 & \\
\hline
\end{tabular}

p $>0.05$

$\left.\dagger^{*} p<0.05\right\}$ Statistical test used in this table and throughout the paper is that described by Bailar and Ederer. ${ }^{8}$

$* * p<0.01\}$

coded separately for each patient and the information transferred to 80-column punch cards. Occupations were classified according to the General Register Office's Classification of Occupations. ${ }^{7}$ The analysis was done on an ICL 1907S computer. In view of the difficulty in defining appropriate denominators in women, little use of the material derived from them could be made in this part of the analysis.

A preliminary analysis of the data supported the suggestion that in men exposure to dust in certain occupations other than the furniture and the boot and shoe manufacturing trades might contribute to the risk of developing nasal cancer. It was therefore decided to extend the occupational data by trying to find out the exact nature of the jobs and the types of dust to which the patient might have been exposed in these occupations. In occupations in which there was a prima facie case that the incidence of nasal cancer was significantly raised, additional information was obtained by interviewing the patients or their relatives. The occupations for which further data were collected included those in orders II, V, and XI (see table 1) and certain other specific occupations. The interviews were carried out by experienced interviewers according to a prearranged plan. Two hundred and forty patients of both sexes came into one or more of these special occupations. In 75 cases $(31.3 \%)$ there were no available contacts, in $19(7.9 \%)$ the patient or relative had requested that they should not be contacted again, and in $20(8.3 \%)$ the consultants concerned did not wish us to contact the patient. This left 136 patients or close relatives to whom a letter was sent requesting permission for an interviewer to visit them: $104(43.3 \%)$ people agreed to be interviewed, $24(10.0 \%)$ did not wish to be interviewed, and eight $(3.3 \%)$ did not reply to two letters. Thus slightly less than half of the total number of patients or relatives in the occupations of special interest were interviewed.

\section{Results}

A total of 1935 cases was ascertained. Of these, 65 $(3.4 \%)$ had been miscoded as nasal cancer, most errors being due to confusion with carcinoma of the skin of the external surface of the nose. There were 242 cases $(12.5 \%)$ of malignant disease of the middle ear and mastoid air sinuses, 19 of nasal cancer $(1.0 \%)$ in non-residents of Britain, and seven ( $0.4 \%)$ in children under the age of 15 that have been excluded. The remainder of the analysis relates to 1602 cases of malignant disease of the nasal cavity and accessory air sinuses diagnosed between the 
Table 2 Cases of cancer of the nasal cavity and accessory sinuses (ICD code 160.0, 160.2-9) in England and Wales 1963-7 by histological type of tumour and sex

\begin{tabular}{|c|c|c|c|c|c|c|}
\hline \multirow[t]{2}{*}{ Histological type of tumour } & \multicolumn{2}{|l|}{ Men } & \multicolumn{2}{|c|}{ Women } & \multicolumn{2}{|c|}{ Both sexes } \\
\hline & No & $\%$ & No & $\%$ & No & $\%$ \\
\hline Squamous & 429 & $46 \cdot 4$ & 280 & $41 \cdot 4$ & 709 & $44 \cdot 3$ \\
\hline Adenocarcinoma & 97 & $10 \cdot 5$ & 33 & 4.9 & 130 & $8 \cdot 1$ \\
\hline Anaplastic & 93 & $10 \cdot 1$ & 96 & $14 \cdot 2$ & 189 & $11 \cdot 8$ \\
\hline Transitional & 32 & $3 \cdot 5$ & 22 & $3 \cdot 2$ & 54 & 3.4 \\
\hline Melanoma & 25 & $2 \cdot 7$ & 23 & $3 \cdot 4$ & 48 & $3 \cdot 0$ \\
\hline Cylindroma & 14 & $1 \cdot 5$ & 22 & $3 \cdot 2$ & 36 & $2 \cdot 2$ \\
\hline Papilloma & 30 & $3 \cdot 2$ & 17 & $2 \cdot 5$ & 47 & $2 \cdot 9$ \\
\hline Other and unclassified & 205 & $22 \cdot 2$ & 184 & $27 \cdot 2$ & 389 & $24 \cdot 3$ \\
\hline Total & 925 & $100 \cdot 0$ & 677 & $100 \cdot 0$ & 1602 & $100 \cdot 0$ \\
\hline
\end{tabular}

years 1963 and 1967 in residents aged 16 years or more and registered with the National Cancer Register of England and Wales.

\section{INCIDENCE BY SEX AND HISTOLOGICAL TYPE} OF TUMOUR

The average annual incidence rates per million for nasal cancer of all histological types combined in England and Wales were 74.0 (men) and 57.8 (women) giving a male/female sex ratio of 1.4:1.

Table 2 shows a breakdown of the material by histological type of tumour and sex. Where opinion differed between the local pathologist and RHC the latter's opinion was selected to ensure that the results would be as closely comparable as possible with our previous work. Squamous tumours composed the largest single subgroup in both men and women. Adenocarcinomas were the second largest group in men, but anaplastic tumours were commoner in women. Apart from these three groups of tumours all the others contributed very small numbers to the totals. The miscellaneous group includes cases where no material was submitted, unclassifiable material, and several rare tumours, none of which contributed more than ten cases to the total.

OCCUPATION: DATA AVAILABLE

The type of occupational data sought in the study differed for men and for women. For men, data were recorded about occupation at the time of diagnosis of the tumour or, in the case of retired men, about the last full-time occupation before retirement. Data were also recorded where available about main occupation-that is, the occupation followed for the longest period-and first occupation on leaving school. Information about occupation at time of diagnosis or on retirement was available in 875 $(94.6 \%)$ of the 925 men but in substantially smaller proportions in the other two categories. For women, information was sought in respect of main occupation outside the home, occupation on leaving school, and, in the case of married women, husband's occupation. Information concerning the main occupation carried out outside the home was available in $377(55.7 \%)$ cases, and for first occupation outside the home on leaving school in 333 (49.2\%). Information about husband's occupation was available for $393(68.5 \%)$ of the married women.

Table 3 gives an analysis of the sources of occupational information by sex. It was possible to obtain information from the patient or a relative in slightly over half of the patients $(52.6 \%)$. The remaining information came either from hospital notes $(8 \cdot 1 \%)$, hospital notes and death certificates $(9.4 \%)$, or death certificates only $(6 \cdot 6 \%)$. Occasionally useful information was obtained from other sources-for example, the general practitioner. Where hospital notes and death certificates were the only sources of occupational data it was assumed that these approximated to the occupation at the time of the diagnosis

Table 3 Sources of occupational information by sex

\begin{tabular}{|c|c|c|c|c|c|c|}
\hline & \multicolumn{2}{|l|}{ Men } & \multicolumn{2}{|c|}{ Women } & \multicolumn{2}{|c|}{ Both sexes } \\
\hline & No & $\%$ & No & $\%$ & No & $\%$ \\
\hline $\begin{array}{l}\text { Patient } \\
\text { Patient's relatives } \\
\text { Hospital notes only } \\
\text { Death certificate only } \\
\text { Death certificate and hospital } \\
\text { Other } \\
\text { No information }\end{array}$ & $\begin{array}{r}147 \\
361 \\
93 \\
89 \\
138 \\
55 \\
42\end{array}$ & $\begin{array}{r}15 \cdot 9 \\
39 \cdot 0 \\
10 \cdot 1 \\
9 \cdot 6 \\
14 \cdot 9 \\
5 \cdot 9 \\
4 \cdot 5\end{array}$ & $\begin{array}{r}94 \\
241 \\
37 \\
16 \\
13 \\
44 \\
232\end{array}$ & $\begin{array}{r}13 \cdot 9 \\
35 \cdot 6 \\
5 \cdot 5 \\
2 \cdot 4 \\
1 \cdot 9 \\
6 \cdot 5 \\
34 \cdot 3\end{array}$ & $\begin{array}{r}241 \\
602 \\
130 \\
105 \\
151 \\
99 \\
274\end{array}$ & $\begin{array}{r}15 \cdot 0 \\
37 \cdot 6 \\
8 \cdot 1 \\
6 \cdot 6 \\
9 \cdot 4 \\
6 \cdot 2 \\
17 \cdot 1\end{array}$ \\
\hline Total & 925 & $100 \cdot 0$ & 677 & $100 \cdot 0$ & 1602 & $100 \cdot 0$ \\
\hline
\end{tabular}


Table 4 Observed and expected numbers of cases of nasal cancer in order II (miners and quarrymen)

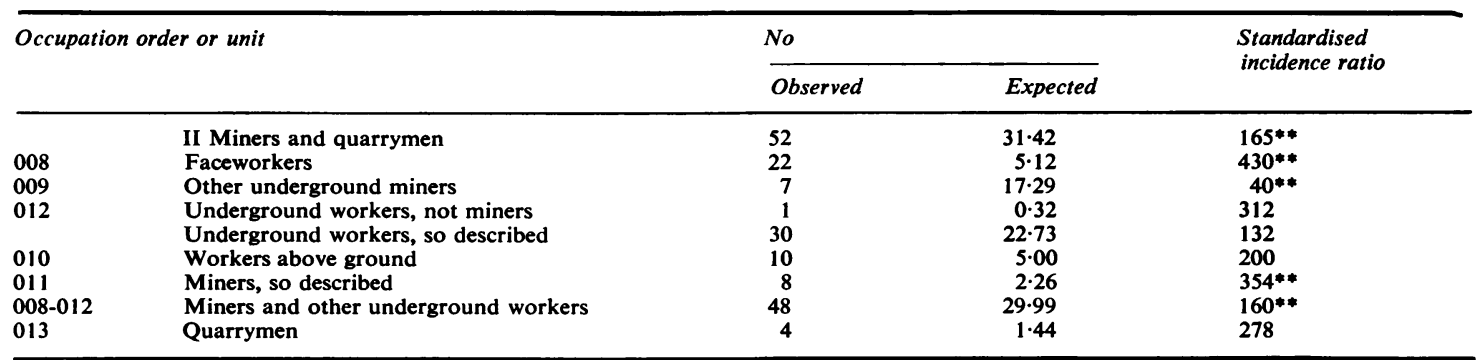

of the tumour or on retirement. The possible biases introduced by this assumption are discussed later.

\section{EFFECT OF OCCUPATION}

In view of the absence of an appropriate denominator for the female cases classified by "main occupation" this part of the analysis is limited to men. In table 3 the cases of nasal cancer observed in men have been distributed among the 27 occupational orders specified in the OPCS classification of occupations. ${ }^{9}$ Expected numbers have been calculated by applying the age-specific incidence rates for all cases (for the age groups $16-44,54-64,65-74,75+$ respectively) to the populations of economically active and retired persons in each occupational order. The 50 men with nasal cancer for whom no occupational data were available were included in the calculations of the agespecific rates.

The analysis confirmed the well-known excesses of nasal cancer among wood workers (VIII) and leather workers (IX). In addition significant excesses of cases were found among miners and quarrymen (II); furnace, forge, foundry and rolling mill workers (V); and clothing workers (XI). Significant deficits of cases were found among construction workers $(\mathrm{XV})$, sales workers (XXII), administrators and managers (XXIV), and professional, technical workers, and artists (XXV). Significant excesses or deficits of cases also occurred in a few specific occupational groups in other orders. A more detailed account of these results follows.

\section{Miners and quarrymen (occupational order II)}

All 48 patients with nasal cancer described as miners at the time their tumour was diagnosed or at the time of retirement except one (a slate miner) were workers in or about coal mines. Four were quarrymen (table 4).

Among miners, a highly significant excess of cases were found among face workers (SIR* 430, $p<0.01$ ).

*Standard incidence ratio $(\mathrm{SIR})=\frac{\text { cases registered }}{\text { expected cases }} \times 100$.
As it is known that, at registration of death, information from relatives exaggerates the number of faceworkers, and a similar bias might have applied here, SIRs were also calculated for all men described as underground workers and for all men classified under the general heading of miners and other underground workers. In the group described as underground workers the excess of cases was not significant (SIR 160, p > 0.05), but in the latter generic group a highly significant excess was shown (SIR 160, $p<0.01$ ). The interpretation of these findings is discussed below.

\section{Furnace and foundry workers}

Part of the excess of nasal cancer in this order was due to the presence of seven cases in process workers of the Mond Nickel Company. All had been employed there before the change in the process that occurred in 1924. ${ }^{10}$ When these cases were excluded, however, there remained significant excesses both in the order as a whole and in furnacemen (table 5). The 22 furnace and foundry workers not associated with the Mond Nickel Company had worked in a wide variety of places in England, principally in the furnaces of steel works. For nine patients information was available about the amount and nature of dust, but there was no obvious common factor apart from coking coal and "furnace dust." Nickel was not mentioned in any of these histories.

\section{Woodworkers and leather workers (occupational orders VIII and IX)}

The results in these orders were consistent with published data. Among woodworkers the SIRs for cabinet and chairmakers $(p<0.01)$ and machinists and other woodworkers were respectively 966,616 , and $293(p<0.05)$, while for carpenters and joiners the SIR of 149 did not reach the conventional limit of significance $(p>0.05)$.

For leather workers, the SIRs for shoemakers and repairers, and for cutters, lasters, and sewers were respectively 714 and $430(p<0.01)$. No cases were 
Table 5 Observed and expected numbers of cases of nasal cancer in order $V$ (furnace and foundry workers)

\begin{tabular}{|c|c|c|c|c|}
\hline \multicolumn{2}{|c|}{ Occupation order or unit } & \multicolumn{2}{|l|}{ No } & \multirow{2}{*}{$\begin{array}{l}\text { Standardised } \\
\text { incidence ratio }\end{array}$} \\
\hline & & Observed & Expected & \\
\hline 021 & $\begin{array}{l}\text { V Furnace and foundry workers } \\
\text { Furnacemen } \\
\text { (excluding } 7 \text { Mond workers) }\end{array}$ & $\begin{array}{r}29 \\
13 \\
6\end{array}$ & $\begin{array}{r}11 \cdot 62 \\
1 \cdot 86 \\
?\end{array}$ & $\begin{array}{r}250 * * \\
699 * * \\
? * *\end{array}$ \\
\hline $\begin{array}{l}022 \\
023-026\end{array}$ & $\begin{array}{l}\text { Rolling tube mill, drawers } \\
\text { Other foundry and furnace workers }\end{array}$ & $\begin{array}{r}4 \\
12\end{array}$ & $\begin{array}{l}1 \cdot 47 \\
8 \cdot 32\end{array}$ & $\begin{array}{l}272 \\
144\end{array}$ \\
\hline
\end{tabular}

reported among tanners.

\section{Clothing workers (occupational order XI)}

The excess of cases in this order is distributed between upholsterers (SIR 305, p $<0.05$ ) and tailors and dressmakers (SIR 372, p $<0.01$ ). Upholsterers are often exposed to wood dust in furniture factories and may therefore have an increased risk of nasal cancer for this reason. ${ }^{3}$ Detailed occupational information was available in four tailors, one of whom had also been exposed to coal dust unloading coal wagons. They stated that some dust from cloth was encountered during their work, but the importance of this is uncertain.

\section{OTHER SPECIFIC OCCUPATIONS}

In addition to the excess of cases already noted in order V (furnace and foundry workers) among workers in the furnaces of steel mills, a significant excess was also found in furnacemen in order III (gas, coke, and chemical workers) (SIR 870, p < 0.01). All six men had worked as furnace attendants in coke ovens in the chemical or coal gas industry. Two had also been coalminers. Information from relatives in five of the six cases confirmed that the men had been heavily exposed to coal or coke dust and furnace fumes for most of their working lives. Excesses of cases were also found among related workers in other orders-namely, labourers in foundries (SIR 427, $\mathrm{p}<0.05$ ) and boiler firemen (SIR 314, p < 0.05) but not among labourers in foundries.

An excess of cases (SIR 385, p < 0.01) was found among coach, carriage, and wagon builders and repairers. This is probably attributable to exposure to wood dust. A significant excess of cases was also found among bakers and pastry cooks (SIR 255, $\mathrm{p}<0.05$ ) but not among flour millers. In all nine bakers there was a clear history of exposure to flour dust, but two men had worked previously in the boot and shoe trade.

A significant excess of cases was found among men described as "printers" but in whom there was no further information about the exact nature of their job (SIR 534, p < 0.01). No excesses of cases were found among compositors or printing press workers, and when the printing trades were considered as a group the excess of cases did not reach the conventional limit of significance (SIR 187, p > 0.05). The findings may therefore be due to lack of information about the occupations of the affected "printers" sufficiently precise to permit accurate classification.

OCCUPATIONAL ORDERS WITH DEFICITS

Significant deficits of cases were noted among construction workers (XV), sales workers (XXII), administrators and managers (XXIV), and professional, technical workers, and artists (XXV).

So far as order XV is concerned the low SIR is almost entirely due to a deficit of men in the generic group of construction workers not elsewhere classified, but as there was an excess of cases in men described as labourers in the building industry ((order XVIII) SIR 186, $p<0.05$ ) the deficiency is probably due to the misclassification of the occupations of some of the men. There was a deficit of cases among bricklayers and tilesetters in order XV. This contrasts with the finding of Bross et al, ${ }^{11}$ who found a significant excess of nasal cancers in brick masons admitted to the Roswell Park Memorial Institute.

Among sales workers (XXII) the principal deficits were among proprieters and managers and salesmen, while among administrators and managers (XXIV) the deficits were generally distributed. There was also a significant deficit of cases among clerks and cashiers (SIR $=63, p<0.01$ ), which was offset in part by an excess of people described as civil servants in order XXIII. Presumably these deficits of cases of nasal cancer reflect the fact that these groups of workers are not generally exposed to dust.

The deficit in order XXV is difficult to interpret because the cases are distributed among no fewer than 28 different occupations. It is worth noting that if the experience of laboratory workers is aggregated the SIR is 67 (9 observed, 13.4 expected; $p>0.05$ ).

INFLUENCE OF OCCUPATION ON HISTOLOGICAL TYPE OF TUMOUR

Information about histological type of tumour was available in $808(92.3 \%)$ of the men and $339(89.9 \%)$ of the women in whom an occupational classification 
could be made respectively at diagnosis or on retirement (men) or for main occupation (women). When tables were made of occupational order versus histological type of tumour a significant excess of adenocarcinomas was shown (29 observed, 6.4 expected) in male woodworkers and among male leather workers ( 9 observed, $2 \cdot 8$ expected). An excess of anaplastic tumours among furnace and foundry men (6 observed, 3.1 expected) was due to the presence in the order of six Mond Nickel workers with this type of tumour. In women there were small excesses of adenocarcinomas in textile workers ( 5 observed, $2 \cdot 3$ expected) and in clothing workers ( 6 observed, 2.4 expected), which did not quite reach the conventional level of statistical significance. No corresponding excesses were found in men, and no other associations between occupation and histological type of tumour were found.

\section{Discussion}

The incidence of nasal cancer reported in this paper is similar to that published for various regional cancer registers in England and for Scotland in the monograph Cancer Incidence in Five Continents. ${ }^{12}$ The higher incidence in men than in women (sex ratio $1 \cdot 4: 1$ ) and the steep increase in incidence with age, the disease being extremely rare in people under $\mathbf{4 0}$ and virtually absent in childhood, have also been described. The figures given here underestimate the true incidence because the National Cancer Register from which the cases were derived is known to be incomplete. The extent of the underascertainment is not known precisely.

The most striking finding of the survey was the excess of cases of nasal cancer in coal miners, in furnacemen in the gas, coke, and chemical industries, and even when the Mond Nickel Company workers are excluded, in furnacemen in order V. All or almost all of these men had been heavily exposed to coal or coke dust. In other occupations exposed to coal or coke dust there was an excess among labourers in foundries and boiler firemen but not among labourers in coke and gas works. Only in the first of these occupations was the SIR significantly different from unity.

Although the consistency of these findings suggests a possible biological relationship between coal and coke dust and nasal cancer they might also be due to bias. In a proportion of the cases the attribution of the occupation of the patient had to be taken from the hospital records or from the death certificates (table 1). So far as the latter of these is concerned direct comparisons have been made by the Registrar General in a sample of deaths between the occupational data given at death and that given at the preceding census. ${ }^{13}$ In this study it was found that in many occupations, particularly those that are physically demanding, such as mining and labouring, many men are so described at death registration who were not classified thus at the previous census. This is likely to stem from a net movement out of a relatively arduous group of occupations during a man's working life and the original arduous occupation being incorrectly recalled and named by the informant at registration of death. The effect of such a bias, which may also operate in relation to hospital records, is to inflate mortality (or incidence) ratios for the occupation concerned. Although ostensibly reliable information was obtained from the patient or relatives or other sources in $29(60.4 \%)$ of the 48 miners and classification of occupation on the basis of the death certificate alone occurred in only eight cases $(16.7 \%)$, the data here are insufficient to settle the question whether there is a biological relationship between the inhalation of coal dust and nasal cancer.

Walter and his colleagues ${ }^{14}$ writing from Strasbourg noted that two of a series of 22 patients with nasal adenocarcinoma were miners. No other reports of nasal cancer in miners have been found. An excess risk of lung cancer but not of nasal cancer has been reported in coke oven workers in the American steel industry ${ }^{15}$ and in Finnish foundrymen. ${ }^{16}$ There was no demonstrable association between coal or coke dust and any particular histological type of tumour in our survey.

In a previous study of nasal adenocarcinomas ${ }^{17}$ a small excess of cases was found among male textile workers (order X) and clothing workers (order XI). More recently Ungzell $e t a^{18}$ found 14 textile workers in a series of 212 Swedish cases of squamous and undifferentiated nasal tumours but no definite conclusion was reached about the significance of this finding. In the present study there was no suggestion of an increased risk in male textile workers (order X, table 2) but a significant increase in SIR was noted in male tailors and dressmakers (order XI). The detailed occupational data derived from questionnaires and interviews showed that most men and women who had manufactured men's clothing regarded the work as dusty.

The evidence for a biological relationship between nasal cancer and the inhalation of flour remains inconclusive. Published reports are anecdotal. ${ }^{418}$ Although in this survey an excess of cases was found in bakers and pastry cooks, there was no parallel increase in flour millers. Among printers the association shown is not strong and may be a chance finding. It is worth noting, however, that in their study at the distribution of the US chemical industry in relation to cancer mortality, a higher than expected number of deaths from nasal cancer was found in 
counties where printing ink was manufactured. ${ }^{19}$

The analysis of occupation by histological type of tumour confirms the special risks of adenocarcinoma in workers in the furniture and boot and shoe industries. It gave no definite indication of any other association between a particular occupation and a specific histological type of tumour.

The approach to the epidemiology of nasal cancer used here has the advantage that it makes it possible to survey the whole spectrum of occupational experience in men. It has the disadvantage that it is subject to serious biases due to the comparability of definition of occupation at the census and in medical records in England and Wales and also is wasteful in that information about previous occupations cannot be used. A case-control study will be necessary to unravel further the relationship of this disease to environmental factors.

This study was supported by a project grant from the Medical Research Council. We are grateful to the patients and their relatives for much valuable information provided at interview and by correspondence and to the staff of the regional cancer registers for their co-operation. We are also most grateful to hospital pathologists for lending us their histological material for review.

\section{References}

1 Hadfield EH, Macbeth RG. Malignant disease of the paranasal sinuses. Journal of Laryngology 1965;79:592-612.

2 Acheson ED, Cowdell RH, Hadfield EH, Macbeth RG. Nasal cancer in woodworkers in the furniture industry. Br Med J 1968;ii:587-96.

3 Acheson ED. Nasal cancer in the furniture and boot and shoe industry. Prev Med 1976;5:295-315.
4 Acheson ED, Cowdell RH, Jolles B. Nasal cancer in the Northamptonshire boot and shoe industry. $\mathrm{Br} \mathrm{Med} J$ 1970;i:385-93.

${ }^{5}$ Cecchi F, Buiatti E, Kriebel D, Nastasi L, Santucci M. Adenocarcinoma of the nose and paranasal sinuses in shoemakers and woodworkers in the province of Florence, Italy. Br J Ind Med 1980;37:222-5.

- World Health Organisation. International classification of injuries, diseases and causes of death. 7th revision. Geneva: WHO, 1957.

? General Register Office. Classification of occupations 1960. London: HMSO, 1966.

${ }^{8}$ Bailar JC, Ederer F. Significance factors for the ratio of a Poisson variable to its expectation. Biometrics 1964;20: 639-43.

9 Office of Population Censuses and Surveys. Occupational mortality 1970-72 England and Wales. London: HMSO, 1978.

${ }^{10}$ Doll R. Cancer of the lung and nose in nickel workers. Br J Ind Med 1958;15:217-23.

11 Bross IDJ, Vjadana E, Houten L. Occupational cancer in men exposed to dust and other environmental hazards. Arch Environ Health 1978;33:300-7.

12 Union International contre le cancer. In : Doll R, Muir C, Waterhouse $\mathrm{J}$, eds. Cancer incidence in five countries. Vol 2. Berlin: UICC, 1970.

${ }^{13}$ Registrar General's Decennial Supplement. England and Wales 1961. Occupational mortality tables. London: HMSO, 1971.

14 Walter P, Stebler S, Schaffer P, Vetter JM, Guerbaoui M. Cylindrical epithelioma of nasal cavities and accessory sinuses. Ann Anat Pathol (Paris) 1976;21:463-76.

15 Redmond CK, Strobino BT, Cypess RH. Cancer experience among coke by-product workers. Ann NY Acad Sci 1976;271:102-15.

${ }^{16}$ Koskela R, Hernberg S, Karava R, Jarvinen E, Nurminen M. A mortality study of foundry workers. Scand J Work Environ Health 1976;2 suppl 1:73-89.

17 Acheson ED, Cowdell RH, Rang E. Adenocarcinoma of the nasal cavity and sinuses in England and Wales. $\mathrm{Br} J$ Ind Med 1972;29:21-30.

18 Ungzell U, Englund A, Westerholm P. Nasal cancer associated with occupational exposure to organic dust. Acta Otolaryngol 1978;86:437-42.

18 Hoover R, Fraumeni JF. Cancer mortality in US counties with chemical industries. Environ Research 1975;9:196 207. 